\title{
Previous sexual experience does not improve estrous behavior and ovulatory activity in seasonally anestrous goats in contact with photo- stimulated bucks
}

\author{
Ilda Graciela Fernández ${ }^{a *}$ (iD) José Alfredo Flores ${ }^{\mathrm{a}}$ (D) | Gerardo Duarte ${ }^{\mathrm{a}}$ (D) |

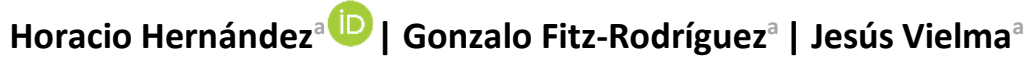

${ }^{a}$ Centro de Investigación en Reproducción Caprina (CIRCA). Postgrado en Ciencias Agrarias. Universidad Autónoma Agraria Antonio Narro, Periférico Raúl López Sánchez C.P. 27054, Torreón, Coahuila, México.

Corresponding author: ilda_fernandez_garcia@yahoo.com.mx

\begin{abstract}
Sexually inexperienced ewes display lower estrous behavior during the first contact with rams. The objective of this study was to determine whether sexually inexperienced anestrous females display estrous behavior and ovulatory activity as the sexually experienced females, and with restricted sexual experience exposed to photo-stimulated bucks. Six bucks were rendered sexually active during the non-breeding season by exposure to artificially long days ( $16 \mathrm{~h}$ of light and $8 \mathrm{~h}$ of darkness per day) for 2.5 months. The first group, sexually experienced females $(n=10)$ had physical contact with two vasectomized bucks, and mating was allowed; the second group, with restricted sexual experience $(n=10)$ had contact with two vasectomized bucks through a wire-mesh fence and mating was prevented; the third group, sexually inexperienced females $(n=9)$ was totally isolated from bucks. At 14-month-old the females were exposed to photostimulated bucks for 15 days. The proportion of females that displayed estrous behavior, ovulations, short and normal ovulatory cycles, and pregnancy rates did not differ between sexually experienced, with restricted sexual experience, and sexually inexperienced ( $P>0.05$, in all variables). Similarly, the ovulation rate did not differ between the three groups of females $(P>0.05)$. However, the interval from introduction of the bucks to the first estrus was shorter in sexually inexperienced females $(P<0.05)$. Therefore, sexually inexperienced anestrous females displayed estrous behavior, ovulation, and pregnancy rate similar to those displayed by sexually experienced and with restricted sexual experience when exposed to photo-stimulated bucks through the male effect.
\end{abstract}

Keywords caprine, male effect, photoperiod, socio-sexual signals

\section{Introduction}

In females of some mammalian species, sexual experience can modify estrous behavior and ovulatory activity. Sexually inexperienced females are those that have not had any socio-sexual contact with males. In sheep (Ovis aries), sexually inexperienced ewes display lower estrous behavior and ovulations compared to those sexually experienced (Murthag et al 1984; Rosciszewska 1985; Gelez et al 2003, 2004). In Sprague-Dawley rats, sexually inexperienced females display lower proceptivity, this is, fewer approaches to males (Norfrey et al 2008). In pigs (Sus scrofa domesticus), sexually inexperienced gilts display a lower mating rate during their first contact with boars compared to sexually experienced gilts that had social contact with boars (Hemsworth et al 1982). Likewise, in grey mouse lemurs (Microcebus murinus) sexually inexperienced females reduce the pregnancy rate compared to those sexually experienced (Radespiel and Zimmermann 2003).

In animals that show reproductive seasonality such as sheep and goats (Capra hircus), the male effect enables conception outside the breeding season (Hawken et al 2008;
Bedos et al 2014). In goats, the introduction of photostimulated bucks in a group of anestrous females increases the frequency of luteinizing hormone pulses and baseline concentration of this hormone within a relatively short period (Ramírez et al 2017). Estrus and ovulation often occur 1-6 days after the introduction of bucks (Bedos et al 2014; Andrade-Esparza et al 2018).

The exposure of bucks to artificially long days over the autumn-winter seasons (November, December, and midJanuary) induces their sexual behavior during the spring (March-April), when animals are normally in a state of sexual rest (Delgadillo et al 2002; Fernández et al 2020). Sexual behavior of bucks stimulates estrus and ovulation in females (e.g., >92\% and >90\%, respectively; Rivas-Muñoz et al 2007; Muñoz et al 2016). Thus, exposure to photo-stimulated bucks during the non-breeding season advances and synchronizes the kidding season of females (Fernández et al 2011). Therefore, in the present study, we tested the hypothesis that sexually inexperienced females could be able to display estrus behavior and ovulatory activity exposed to photostimulated bucks. The objective of the study was thus to 
determine whether sexually inexperienced anestrous females display estrous behavior and ovulatory activity as the sexually experienced, and those with restricted sexual experience in contact with photo-stimulated bucks.

\section{Materials and Methods}

\subsection{Experimental animals and description of treatments}

The present study was carried out in Torreon in the State of Coahuila, Mexico ( $26^{\circ} 23^{\prime} \mathrm{N}, 104^{\circ} 47^{\prime}$ W; 1200 m a.s.I.). Torreon has a semi-arid climate (Köppen: $\mathrm{BS}_{0} \mathrm{hw}$ ). Creole goats were used. In this area, bucks display sexual rest from January to May, and females isolated from bucks display anestrous from January-February to August-September (Delgadillo et al 1999; Duarte et al 2008). Kids were born on January $12 \pm 1$ day (mean value \pm standard error of the mean) and were weaned at 40 days of age (body weight $(B W)=7.2$ $\pm 0.1 \mathrm{~kg}$ ). When the kids were three months old ( $\mathrm{BW}=10.1 \pm$ $0.2 \mathrm{~kg}$ ), the females were randomly separated into three groups. The first group $(n=10)$ was treated in such a way that they would be sexually experienced. This group was placed in a pen $(5 \times 5 \mathrm{~m})$ with a pair of 2-year-old vasectomized bucks, with the females having complete physical, visual, auditory, olfactory, and tactile contact with the vasectomized bucks, and mounting with intromission were allowed during the breeding season. The second group $(n=10)$ was treated in such a way that they would be with restricted sexual experience. The females were placed in a pen $(5 \times 4 \mathrm{~m})$ and had restricted visual, auditory, olfactory, and tactile contact with a pair of 2-year-old vasectomized bucks through a wiremesh fence. Thus, mating in these females was prevented. To avoid contact between sexually experienced females, and those with restricted sexual experience, the pens were separated by a distance of more than $150 \mathrm{~m}$. In both groups of females, the vasectomized bucks remained in the same conditions from mid-April to mid-January. Afterward, the vasectomized bucks were withdrawn from females. The third group $(n=9)$ was treated in such a way that they would be sexually inexperienced. This group was placed in a pen $(5 \times 5$ $\mathrm{m})$ and the females were isolated from bucks. To avoid contact between sexually inexperienced females and bucks, the pen was separated by a distance of more than $6000 \mathrm{~m}$. Females and bucks were fed ad libitum with alfalfa hay $(21 \%$ crude protein, $1.95 \mathrm{Mcal} / \mathrm{kg} \mathrm{ME}$ ). The females received $200 \mathrm{~g}$ per day of commercial concentrate (18\% crude protein, 2.05 $\mathrm{Mcal} / \mathrm{kg} \mathrm{ME}$ ), following their nutritional requirements, from weaning until the end of the study. The bucks received $300 \mathrm{~g}$ per day of commercial concentrate (14\% crude protein, 2.5 $\mathrm{Mcal} / \mathrm{kg} \mathrm{ME}$ ) throughout the study. Fresh, clean water and mineral salts were always available for both bucks and females.

\subsection{Photoperiodic treatment of bucks}

Sexually experienced bucks $(n=6)$ of 2-year-old were subjected to artificially long days ( $16 \mathrm{~h}$ of light and $8 \mathrm{~h}$ of darkness per day) for 2.5 months from November 1 to January 15. Each of these days was composed of periods of artificial light (06:00-08:00 $\mathrm{h}$ and 18:00-22:00 h) and natural light (08:01-17:59 h). The artificial light periods were controlled with a digital timer. The intensity of the artificial light was at least $300 \mathrm{~lx}$, with the light positioned laterally to the eyes of the bucks. The bucks were placed in an open, shaded pen during this treatment. The photoperiodic treatment stimulates testicular growth, testosterone secretion, odor, and sexual behavior during the sexual rest period (Delgadillo et al 2002).

\subsection{Assessment of anestrous females}

When the females were 14-month-old, their anovulatory status was confirmed based on the absence of corpora lutea. In March, two ultrasound examinations were carried out 20 and 10 days before introducing the bucks in the female groups. The ultrasound device used was an Aloka SSD-500 (Tokyo, Japan) equipped with a $7.5 \mathrm{MHz}$ transducer. Three days before starting the study, BW and body condition score were measured for experimental female groups and averaged $28.3 \pm 1.8 \mathrm{~kg}, 27.0 \pm 1.9 \mathrm{~kg}$ and $26.1 \pm 1.2 \mathrm{~kg}$ and 2.6 $\pm 0.1,2.5 \pm 0.08$ and $2.5 \pm 0.07$ for sexually inexperienced females, with restricted sexual experience, and sexually experienced females, respectively. The body condition score was determined on a scale ranging from 1 (emaciated) to 4 (fat) (Walkden-Brown et al 1997).

\subsection{The male effect}

On 26 March (day 0, 08:00 h), each group of females was exposed to one buck. The bucks remained with the females for 15 days at all times. Bucks were interchanged twice by day at 08:00 $\mathrm{h}$ and 18:00 $\mathrm{h}$ in the groups of females.

\subsection{Measurements}

To confirm that the bucks were sexually active, their sexual behavior was observed from 08:00 to 08:20 $\mathrm{h}$ and from 18:00 to $18: 20$ on days 0,1 , and 2 after their introduction to the female groups. The sexual behavior of bucks such as nudging, anogenital sniffing, mounting attempts, and mounts with intromission was documented (Fernández et al 2018).

\subsubsection{Blood samples and progesterone assay}

To measure plasma progesterone levels, blood samples were collected by jugular venipuncture in 5-ml tubes containing $30 \mu \mathrm{L}$ of sodium heparin. Plasma was obtained by centrifugation of the blood samples at $3500 \times \mathrm{g}$ for $30 \mathrm{~min}$ and then stored in $3.5-\mathrm{mL}$ tubes at $-20^{\circ} \mathrm{C}$ until hormone concentrations were measured. Progesterone levels were determined on days 0-15 after the introduction of the males to the female groups. Plasma progesterone concentration was determined using an RIA (COAT-A-COUNT SIEMENS radioimmunoassay kit) according to the technique described and validated by Grajales et al (2010). The sensitivity of the assay was $0.02 \mathrm{ng} / \mathrm{mL}$. The inter-and intra-assay coefficients of variation were $4.7 \%$ and $5.5 \%$, respectively.

\subsubsection{Estrous behavior}


The latency to the first estrus is the time elapsed in hours from the introduction of the bucks to the first observation of estrus in each female. Estrous behavior was registered twice daily by direct visual observation from 08:00 to $09: 00 \mathrm{~h}$ and from $18: 00$ to $19: 00 \mathrm{~h}$ for 15 days after the introduction of the bucks in the female groups. A female in estrus typically acquires an immobilized posture that facilitates mating by the buck (Fatet et al 2011). Pregnancy rates (the number of pregnant females/number of females exposed to bucks) was determined by transrectal ultrasound on day 36 after the introduction of the bucks.

\subsubsection{Ovulatory activity}

The ovulatory activity was inferred based on plasma progesterone levels. Progesterone levels $\geq 0.5 \mathrm{ng} / \mathrm{mL}$ in at least one blood sample was considered indicative of ovulatory activity. A short ovulatory cycle was inferred when progesterone increased $(\geq 0.5 \mathrm{ng} / \mathrm{mL}$ ) and then decreased to basal levels during the first 6 days, and increased again around 9-10 days after the introduction of the bucks. A normal ovulatory cycle was inferred when progesterone continuously increased during the first 6 days after the introduction of the bucks to the female groups (Chemineau et al 2006; Bedos et al 2010; Andrade-Esparza et al 2018). The proportion of females that ovulated was determined by dividing the number of females that ovulated by the total number of females exposed to bucks. Ovulation rate (number of corpora lutea/number of females that ovulated) was measured on day 21 after the introduction of the bucks in female groups and was based on the presence and number of corpora lutea detected by a transrectal ultrasound of each female.

\subsection{Ethical note}

All procedures performed in this study were following the protocol of the Official Mexican Rule NOM-062-ZOO1999 of the Secretaría de Agricultura, Ganadería, Desarrollo Rural, Pesca y Alimentación (SAGARPA 2001), which provides technical specifications for the production, care, and use of laboratory animals.

\subsection{Statistical analysis}

Shapiro-Wilk and Levene's tests were used to evaluate the normality and homogeneity of the variances of data for the latency to the first estrous behavior and ovulation rate. Because the assumption of normality was not met, the MannWhitney $U$ test was used to compare the groups of females. The proportions of females displaying estrous behavior, ovulating, having short and normal ovulatory cycles, and the rate of pregnancy was compared between the groups of females with a Fisher's exact test. Due to the low number of bucks used, it was not possible to perform any statistical analysis on their sexual behavior ( 2 bucks by females group). Data were expressed as mean values \pm standard error of the mean. Analyses were performed with the statistical package SYSTAT version 13.00 .05 (2009).

\section{Results}

\subsection{Sexual behavior of bucks}

Photo-stimulated bucks displayed high sexual behavior such as nudging, anogenital sniffing, mounting attempts, and mounts with intromission (Figure 1).

\subsection{Estrous behavior, ovulatory activity, and pregnancy rate}

The interval from buck introduction to the first estrus was significantly shorter in sexually inexperienced females ( $P$ $<0.05$; Table 1). Whereas the proportion of females showing estrous behavior during the 15 days of contact with photostimulated bucks did not differ between the three groups of females ( $P>0.05$; Table 1 and Figure 2). The cumulative and daily proportions of females showing estrous behavior are depicted in Figure 2. The occurrences of short and normal ovulatory cycles, the proportion of females ovulating, and ovulation rate did not differ significantly between the three groups of females ( $P>0.05$; Table 1 and Figure 3 ). Likewise, pregnancy rate did not differ significantly between the three groups of females $(P>0.05$; Table 1$)$.

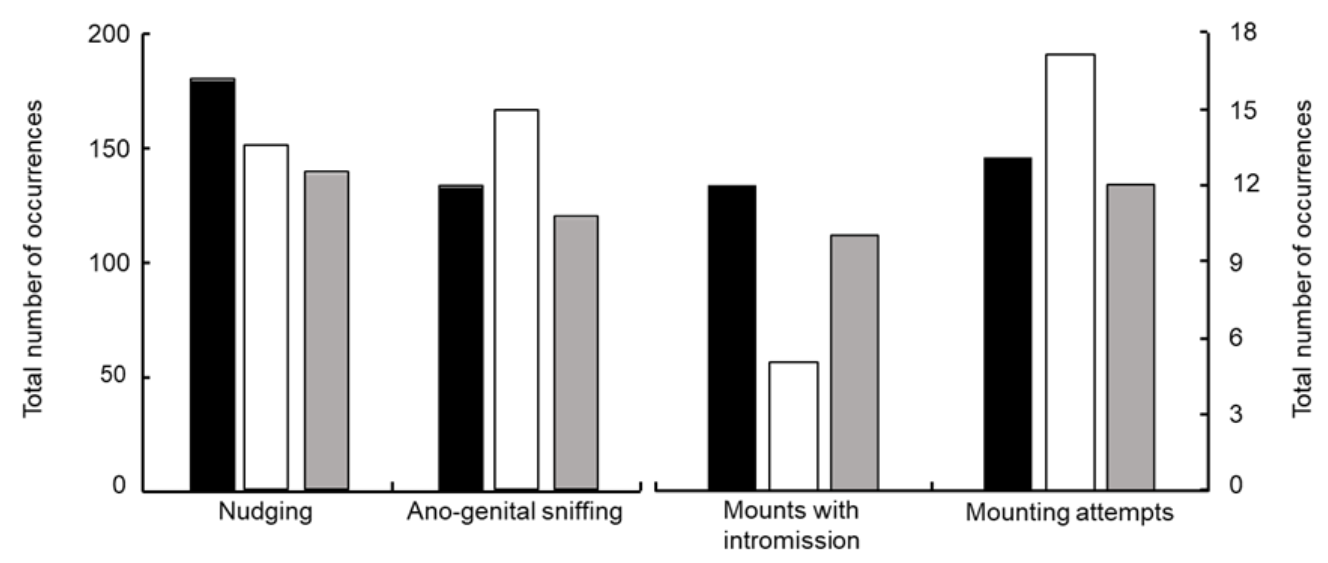

Figure 1 Sexual behavior of photo-stimulated bucks exposed to sexually experienced females (black bar), with restricted sexual experience (white bar), and sexually inexperienced (gray bar). Sexual behavior of bucks was recorded the first 3 days of contact with females. Bucks were subjected to artificially long days ( $16 \mathrm{~h}$ of light and $8 \mathrm{~h}$ of darkness per day) for 2.5 months from 1 November to 15 January, after which they were held under natural photoperiod conditions. 


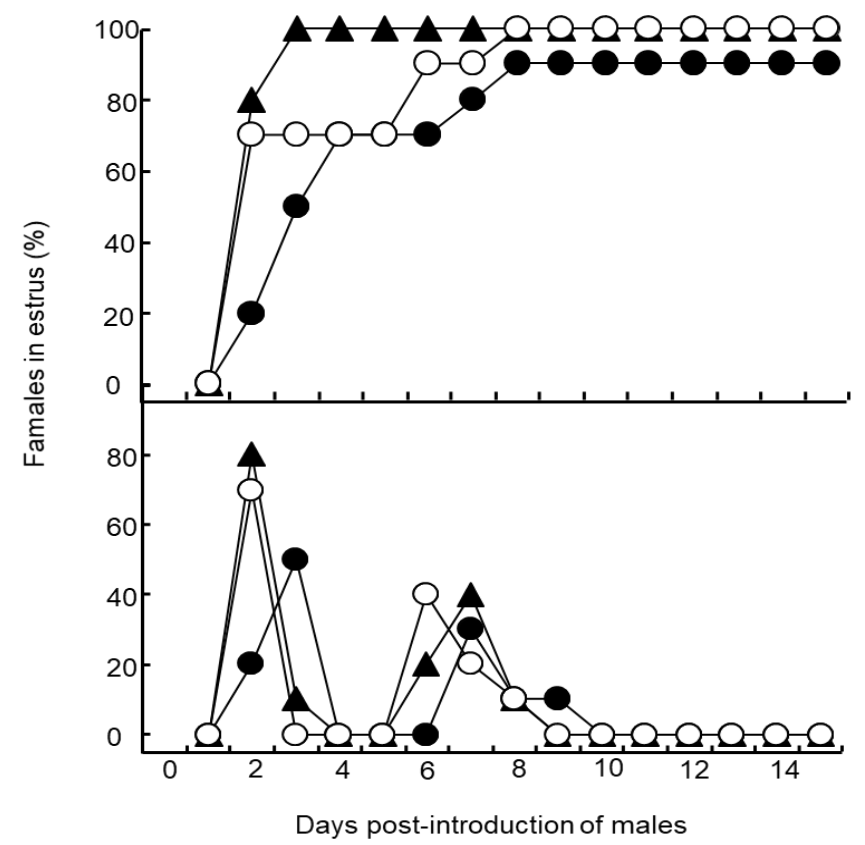

Figure 2 Cumulative (top) and daily (bottom) proportion of females displaying estrous behavior. Sexually experienced females ( $\bullet$ ), with restricted sexual experience (0), and sexually inexperienced $(\boldsymbol{\Delta})$. Females were exposed to photo-stimulated bucks for 15 days. Bucks were subjected to artificially long days ( $16 \mathrm{~h}$ of light and $8 \mathrm{~h}$ of darkness per day) for 2.5 months from November 1 to January 15, after which they were held under natural photoperiod conditions.

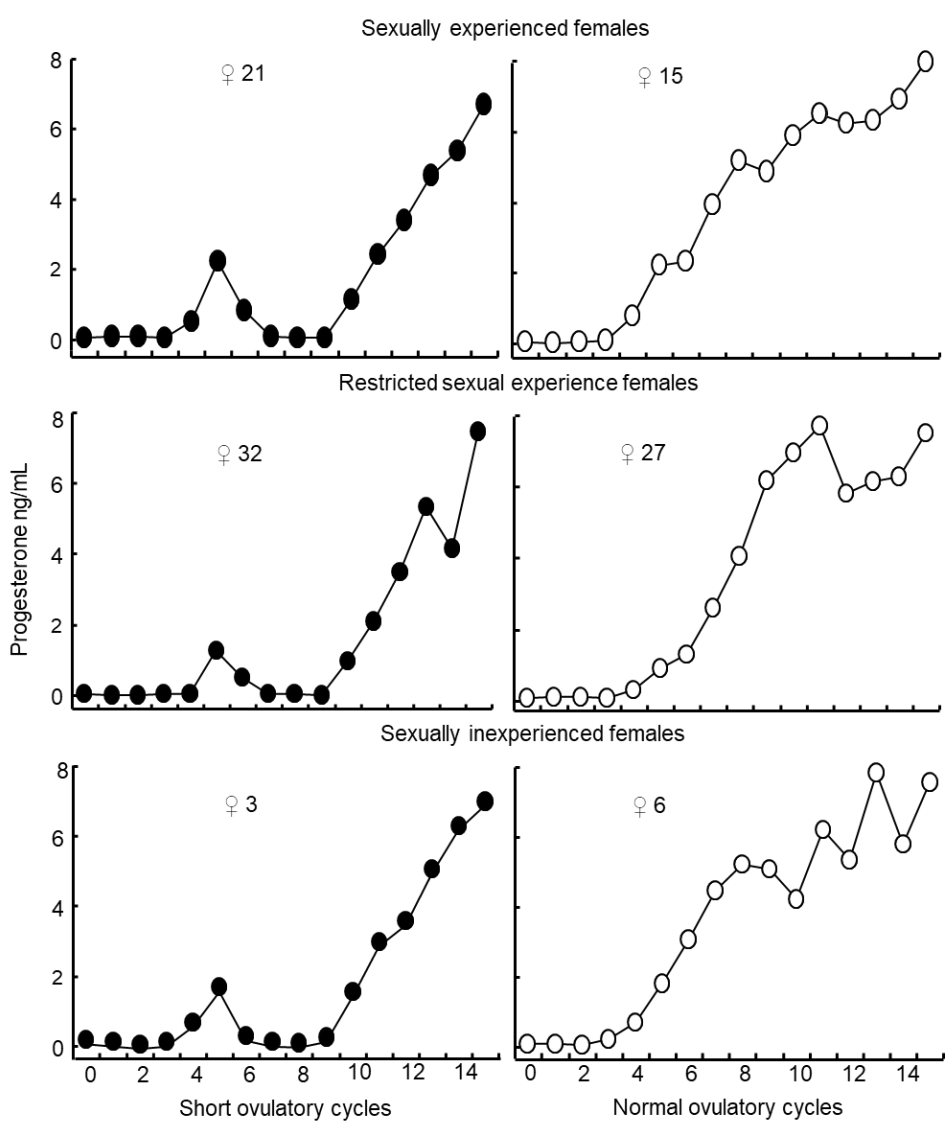

Days post-introduction of bucks

Figure 3 Plasma progesterone concentration in sexually experienced females, with restricted sexual experience, and sexually inexperienced. Females were exposed to photo-stimulated for 15 days. Bucks were subjected to artificially long days ( $16 \mathrm{~h}$ of light and $8 \mathrm{~h}$ of darkness per day) for 2.5 months from November 1 to January 15, after which they were held under natural photoperiod conditions. Examples of short ovulatory cycles $(\bullet)$ and normal ovulatory cycles (o) following to the introduction of the bucks into female groups. 
Table 1 Estrous behavior, ovulatory activity, and pregnancy rate in sexually experienced females, with restricted sexual experience, and sexually inexperienced. Females were exposed to photo-stimulated bucks for 15 days. Bucks were subjected to artificially long days (16 $\mathrm{h}$ of light per day and $8 \mathrm{~h}$ of darkness per day) from November 1 to January 15, after which they were held under natural photoperiod conditions.

\begin{tabular}{|c|c|c|c|c|c|c|c|c|}
\hline Groups of females & $n$ & $\begin{array}{l}\text { Interval to the } \\
\text { first estrus in } \\
\text { hours } \\
( \pm \text { SEM) }\end{array}$ & $\begin{array}{l}\text { Short } \\
\text { ovulatory } \\
\text { cycles } \\
(\%)\end{array}$ & $\begin{array}{l}\text { Normal } \\
\text { ovulatory } \\
\text { cycles } \\
(\%)\end{array}$ & $\begin{array}{c}\text { Estrous } \\
\text { behavior in } 15 \\
\text { days } \\
\text { (\%) }\end{array}$ & $\begin{array}{c}\text { Ovulation } \\
\text { (\%) }\end{array}$ & $\begin{array}{l}\text { Ovulation } \\
\text { rate } \\
( \pm \text { SEM) }\end{array}$ & $\begin{array}{c}\text { Pregnancy } \\
\text { rate } \\
\text { (\%) }\end{array}$ \\
\hline $\begin{array}{l}\text { Sexually } \\
\text { experienced }\end{array}$ & 10 & $49.7 \pm 7^{a}$ & 50 & 40 & 90 & 90 & $1.0 \pm 0.19$ & 70 \\
\hline $\begin{array}{l}\text { With restricted } \\
\text { sexual experience }\end{array}$ & 10 & $39.4 \pm 3^{a}$ & 70 & 30 & 100 & 100 & $1.3 \pm 0.15$ & 80 \\
\hline $\begin{array}{l}\text { Sexually } \\
\text { inexperienced }\end{array}$ & 9 & $30.5 \pm 3^{b}$ & 60 & 30 & 100 & 100 & $1.3 \pm 0.15$ & 88 \\
\hline
\end{tabular}

\section{Discussion}

In the present study, the hypothesis stated was that sexually inexperienced females could be able to display estrous behavior and ovulatory activity exposed to photostimulated bucks. The results of the present study agreed with this hypothesis. Estrous behavior, ovulatory and reproductive responses were similar between sexually experienced females, with restricted sexual experience, and sexually inexperienced. It was found that the present results are comparable to those reported previously by Fernández et al (2011), wherein sexual response did not differ between sexually inexperienced and sexually experienced females exposed to photo-stimulated bucks; however, in that study sexually experienced females were defined as those that had auditory, visual, and olfactory contact from bucks, and mating was prevented; then, these group of females had no sexual experience.

Besides, in this study, sexually experienced females, with restricted sexual experience, or sexually inexperienced displayed a high percentage of estrous behavior, with these results in agreeance with a previous study in which multiparous females were exposed to photo-stimulated bucks (Muñoz et al 2016; Fernández et al 2018). Our photostimulated bucks received artificially long days from November 1 to January 15, subsequently received the natural photoperiod. This photoperiodic treatment of artificially long days promotes the increase of testosterone secretion, sexual behavior, and odor during the sexual rest period (Delgadillo et al 2002; Fernández et al 2018). Then, the current research shows that the lack of sexual experience does not influence estrous behavior in anestrous females exposed to photostimulated bucks. In contrast, sexually inexperienced ewes were reluctant to allow themselves to be mounted and served by a ram (Rosciszewska 1985).

Interestingly, our results show that sexually inexperienced females displayed shorter the interval from introduction of the bucks to the first estrous behavior compared to sexually experienced females, and those with restricted sexual experience. Then, sexually inexperienced females displayed high attraction to bucks, from their first contact with them. Also, sexually inexperienced females experienced for the first time the sensory signals of the bucks such as seeing, smelling, touching, and hearing. Then, the first social encounter between anestrous females and photostimulated males, had a positive effect because the hypothalamus-pituitary-ovarian axis was activated. In contrast, a previous study found that sexually inexperienced ewes, adults or young, displayed less proceptive behavior to rams. Perhaps this response was a consequence of the low sexual activity displayed by the rams (Gelez et al 2004).

Likewise, our results show that the proportion of short and normal ovulatory cycles did not differ between sexually experienced females, with restricted sexual experience, and sexually inexperienced. A consequence of the high ovarian activity was the high pregnancy rate recorded in sexually experienced females, with restricted sexual experience, or sexually inexperienced. Our results are in agreeance with a previous study in which sexually inexperienced females registered high ovulatory activity when exposed to males (Walkden-Brown et al 1993); in both cases, the females were exposed to bucks by the male effect. In contrast, in sheep, the proportion of ewes that ovulated was lower in sexually inexperienced than the experienced ones (Murtagh et al 1984).

Pregnancy rates recorded in the current study did not differ between sexually experienced females, with restricted sexual experience, or sexually inexperienced, as mentioned above. Likewise, in a previous study sexually inexperienced and sexually experienced ewes recorded a similar percentage of pregnancies when exposed to rams during the breeding season (Rosciszewska 1985); however, in the current study, the percentage of pregnancies was higher. This difference could be attributed to the fact that the females were exposed to photo-stimulated bucks which displayed high sexual behavior that contributed to better, and more stimulating sexual activity in anestrous females.

Therefore, the results of the current study clearly show that previous sexual experience acquired during mating is not a prerequisite for improving estrous behavior and ovulatory activity in anestrous females in contact with photostimulated bucks. Thus, the current results differ from a 
previous study that suggested that ewes need more sexual interactions with rams to improve their sexual response (Hawken et al 2008). However, it was not clear whether the rams used in the previous study displayed high sexual behavior.

Therefore, sexually experienced females, with restricted sexual experience, or sexually inexperienced females displayed similar estrous behavior, ovulatory activity, and pregnancy rate, because they were exposed to sexually photo-stimulated bucks. As mentioned above, when sexually experienced females, with restricted sexual experience, or sexually inexperienced females were exposed to photo-stimulated bucks, they displayed also a level high of sexual behavior such as nudging, anogenital sniffing, mounting attempts, and mounts with intromission. Although in the present study, the odor was not measured in our experimental bucks, a previous study indicated that buck odor contributes to inducing ovulation in anestrous females, as was observed in photo-stimulated and non-sedated males exposed to anestrous females (Martínez-Alfaro et al 2014). Moreover, Muñoz et al (2016) and Fernández et al (2020) reported that the level high of sexual behavior displayed by photo-stimulated males is an essential component to induce estrous behavior and ovulatory activity in anestrous female goats.

\section{Conclusions}

The results of the present study show that sexually inexperienced female goats that had not mated before experiencing the male effect displayed estrous behavior, ovulatory activity, and pregnancy rate similar to those displayed by sexually experienced females, and with restricted sexual experience in contact with photostimulated bucks by means of the effect male.

\section{Acknowledgments}

The authors are grateful to Clara Murcia of the Departamento de Reproducción of the Facultad de Medicina Veterinaria y Zootecnia, Universidad Nacional Autónoma de México by hormonal determinations. They thank all members of the Centro de Investigación en Reproducción Caprina (CIRCA) of the Universidad Autónoma Agraria Antonio Narro for their help during the study.

\section{Conflict of Interest}

The authors declare that they have no conflict of interest.

\section{Funding}

This research did not receive any specific grant funding agencies in the public commercial, or not-for-profit sectors.

\section{References}

Andrade-Esparza JD, Espinoza-Flores LA, Hernández $\mathrm{H}$, Chemineau $\mathrm{P}$, Keller M, Delgadillo JA (2018) Extensive management conditions do not modify the frequency of short ovulatory cycles in progesterone-treated does exposed to sexually active males. Animal Reproduction Science 199:40-44.
Bedos M, Flores JA, Fitz-Rodríguez G, Keller M, Malpaux B, Poindron P, Delgadillo JA. (2010) Four hours of daily contact with sexually active males is sufficient to induce fertile ovulation in anestrous goats. Hormones and Behavior 58:473-477.

Bedos M, Duarte G, Flores JA, Fitz-Rodríguez $G$, Hernández $H$, Vielma J, Fernández IG, Chemineau P, Keller M, Delgadillo JA (2014) Two or 24 h of daily contact with sexually active males results in different profiles of $\mathrm{LH}$ secretion that both lead to ovulation in anestrus goats. Domestic Animal Endocrinology 48:93-99.

Chemineau P, Pellicer-Rubio MT, Lassoued N, Khaldi G, Monniaux D (2006) Male-induced short oestrous and ovarian cycles in sheep and goats: a working hypothesis. Reproduction Nutrition and Development 46:417-429.

Delgadillo JA, Canedo GA, Chemineau P, Guillaume D, Malpaux B (1999) Evidence for annual reproductive rhythm independent of food availability in male creole in subtropical northern Mexico. Theriogenology 52:727-737.

Delgadillo JA, Flores JA, Véliz G, Hernandez H, Duarte G, Vielma J, Poindron $P$, Chemineau $P$, Malpaux $B$ (2002) Induction of sexual activity in lactating anovulatory female goats using male goats treated only with artificially long days. Journal of Animal Science 80:2780-2786.

Duarte G, Flores, JA, Malpaux B, Delgadillo JA (2008) Reproductive seasonality in female goats adapted to a subtropical environment persist independently of food availability. Domestic Animal Endocrinology 35:362370.

Fatet A, Pellicer-Rubio MT, Leboeuf B (2011). Reproductive cycle of goats. Animal Reproduction Science 124:211-219.

Fernández IG, Luna-Orozco JR, Vielma J, Duarte G, Hernández $H$, Flores JA, Gelez H, Delgadillo JA (2011) Lack of sexual experience does not reduce the responses of $\mathrm{LH}$, estrus or fertility in anestrous goats exposed to sexually active males. Hormones and Behavior 60:484-488.

Fernández IG, Flores Medina E, Flores JA, Hernández H, Vielma J, FitzRodríguez G, Duarte G (2018) Absence of previous sexual experience did not modify the response of anoestrous goats to photo-stimulated bucks in Spring. Italian Journal of Animal Science 17:306-311.

Fernández IG, Loya-Carrera J, Sifuentes-Lamónt P, Duarte G, Flores JA, Grimaldo E, Hernández H, Ulloa-Arvizu R, Andrade-Esparza J (2020). Social isolation not inhibit sexual behaviour and testosterone secretion in sexually inexperienced photo-stimulated bucks in contact with seasonally anoestrous goats. Italian Journal of Animal Science 19:989-996.

Gelez H, Lindsay DR, Blanche D, Martin GB, Fabre-Nys C (2003) Temperament and sexual experience affect females sexual behavior in sheep. Applied Animal Behaviour Science 84:81-87.

Gelez H, Archer E, Chesneau D, Lindsay D, Fabre-Nys C (2004) Role of experience in the neuroendocrine control of ewes' sexual behavior. Hormones and Behavior 45:190-200.

Grajales H, Hernández A, Prieto E. (2010) Niveles de progesterona durante el ciclo normal y silencioso en bovinos en el trópico colombiano. Revista MVZ Córdoba 15:2060-2069.

Hawken PAR, Evans ACO, Beard AP (2008) Prior exposure of maiden ewes to rams enhances their behavioural interactions with rams but is not a prerequisite to their endocrine response to the ram effect. Animal Reproduction Science 108:13-21.

Hemsworth PH, Cronin GM, Hansen C (1982) The influence of social restriction during rearing on the sexual behavior of the gilt. Animal Production 35:35-40.

Martínez-Alfaro JC, Hernández H, Flores JA, Duarte G, Fitz-Rodríguez G, Fernández IG, Bedos M, Chemineau P, Keller M, Delgadillo JA, Vielma J (2014) Importance of intense male sexual behavior for inducing the preovulatory LH surge and ovulation in seasonally anovulatory female goats. Theriogenology 82:1028-1035.

Muñoz AL, Bedos M, Aroña RM, Flores JA, Hernández $H$, Moussu C, Briefer EF, Chemineau P, Keller M, Delgadillo JA (2016) Efficiency of the male effect with photostimulated bucks does not depend on their familiarity with goats. Physiology and Behavior 158:137-142. 
Murtagh JJ, Gray SJ, Lindsay DR, Oldham CM (1984) The influence of the ram effect in 10-11 month old Merino ewes on their subsequent performance when introduced to rams again at 15 months of age. Proceedings of the Australian Society of Animal Production 15, 490-493.

Nofrey B, Rocha B, Lopez HH, Ettenber A (2008) The effects of sexual experience and estrus on male-seeking motivated behavior in the female rat. Physiology and Behavior 95:533-538.

Radespiel U, Zimmermann E (2003) The influence of familiarity, age, experience and female mate choice on pregnancies in captive grey mouse lemurs. Behavior. 140:301-318.

Ramírez S, Bedos M, Chasles M, Hernández H, Flores JA, Vielma J, Duarte $G$, Retana-Márquez MS, Keller M, Chemineau P (2017) Fifteen minutes of daily contact with sexually active male induces ovulation but delays its timing in seasonally anestrous goats. Theriogenology 87:148-153.

Rivas-Muñoz R, Fitz-Rodríguez G, Poindron P, Malpaux B, Delgadillo JA (2007) Stimulation of estrous behavior in grazing female goats by continuous or discontinuous exposure to males. Journal of Animal Science 85:1257-1263.
Rosciszewska ZE (1985) The influence of earlier mating experiencie of ewes on their subsequent mating behaviour and reproductive performance. Animal Reproduction Science 9:223-229.

SAGARPA, Secretaría de Agricultura, Ganadería, Desarrollo Rural, Pesca y Alimentación. Norma Oficial Mexicana NOM-062-ZOO, Especificaciones técnicas para la producción, cuidado y uso de los animales de laboratorio. Diario Oficial de la Federación, México D.F., 22 Agosto 2001.

SYSTAT 13.00.05. 2009. Systat Software, Inc., Chicago, IL, USA.

Walkden-Brown SW, Restall BJ, Henniawati (1993) The male effect in the Australian cashmere goat. 2 . Role of olfactory cues from the male. Animal Reproduction Science 32:55-67.

Walkden-Brown SW, Restall BJ, Scaramuzzi R J, Martin GB, Blackberry MA (1997) Seasonality in male Australian cashmere goats: long term effects of castration and testosterone or oestradiol treatment on changes in $\mathrm{LH}, \mathrm{FSH}$ and prolactin concentrations, and body growth. Small Ruminant Research 26:239-252. 